\title{
UNA REFLEXIÓN JURÍDICO-ECONÓMICA E INSTITUCIONAL DEL SISTEMA DE JUSTICIA CIVIL EN EL PERÚ*
}

Rubén Méndez Reátegui**

\begin{abstract}
RESUMEN
El presente trabajo desarrolla algunos de los presupuestos iniciales del Análisis Económico del Derecho y del moderno análisis neo-institucional con relación al entendimiento del Sistema de Justicia Civil, considerando como caso de estudio el peruano. El primer objetivo consiste en sugerir una respuesta a interrogantes que aparentemente no denotan mayor complejidad como ¿debemos demandar? A partir de esta primera aproximación, se introduce el segundo objetivo del documento el cual es abordar la problemática de los costos y beneficios, los efectos externos y de las dinámicas propias del Sistema en mención. El tercer objetivo es presentar una discusión del carácter público del bien (justicia civil) que un sistema legal puede proveer. Finalmente, este conjunto de elocuciones intenta constituirse como punto de partida de una discusión más amplia: el problema del costo
\end{abstract}

Fecha Recibido: Enero 6 de 2014 • Fecha Aceptado: mayo 30 de 2014

* Artículo inédito.

*** Rubén Méndez R. es Ph.D (c) y miembro del equipo académico del Departamento de Economía de la Universidad de Macquarie (Sídney -Australia). Asimismo, ostenta estudios de pregrado en Derecho y CCPP por la UNMSM (Perú) y Economía (London University). Posee un M.A. en Economía por la UNED, un M.A. en Economía Aplicada y un MSc. en Marco Institucional y Crecimiento Económico por la Universidad Rey Juan Carlos y un MSc. en Análisis Económico y Políticas Públicas por la Universidad de Salamanca. Actualmente se desempeña como académico visitante de la Universidad de Macquarie (MqU) en la Universidad Complutense de Madrid (departamento de Historia e Instituciones Económicas I) y la Universidad de Salamanca en España (Departamento de Economía Aplicada en la Facultad de Derecho). 
social que produce el imperante y deficiente diseño institucional (reglas y agentes) para la provisión de justicia, el cual tiene como efecto la prolongación de un contexto que el autor anteriormente ha descrito como de ausencia de coordinación institucional ${ }^{1}$ y estancamiento del Perú como una sociedad no estructurada. ${ }^{2}$

Palabras clave: Sistema de Justicia Civil, demanda, juicio, bien público, costo social, coordinación institucional, reforma y cambio institucional.

\begin{abstract}
This paper develops some of the assumptions of economic analysis of law and the modern neo - institutional analysis to understand the Peruvian Civil Justice System, as a case study. The first aim is to answer the following question: To what extent should we start a trial? Secondly, the paper explores the dynamics (costs and benefits and external effect) of the Peruvian justice system. Finally, the third aim is to present a discussion of the public good "civil justice" that a legal system can produce. Therefore, this paper seeks to establish a starting point for further discussion surrounding the difficulties with social cost which, in turn, produces the prevailing poor institutional design (rules and agents) in Peru's judicial system. This scenario only prolongs the lack of institutional coordination and the stagnation of Peru as an unstructured society ${ }^{3}$.
\end{abstract}

Key words: Civil justice system, complaint, trial, public's goods, social cost, institutional organization, reform and institutional change.

\title{
INTRODUCCIÓN
}

Toda sociedad que intente alcanzar el bienestar de los individuos que la conforman debe tener en consideración que su objetivo principal radica en establecer las condiciones más adecuadas para una convivencia social armónica, que reduzca los daños y, por ende, disminuya los costos a terceros.

De lo expuesto se desprende que, si un Estado desea establecer reglas que contribuyan con la existencia de un orden en la sociedad para que esta evolucione hacia la cohesión social y el respeto mutuo, deberá buscar los mecanismos

1 MÉNDEZ, R., "Entrepreneurship, Institutions in a Changing Environment", URJC and IJM VI Austrian Economics Conference. Madrid: URJC/Instituto Juan de Mariana, 2013.

2 MÉNDEZ, R., "An Introduction to Institutional Coordination", Working paper - GLEA Lecture Series 2013, Italia: Free University of Bolzano, 2013.

3 MÉNDEZ, R., "Entrepreneurship.... Op. cit.; MÉNDEZ, R., "An introduction.... Op. cit. 
que acerquen su actividad regulatoria a la realidad ${ }^{4}$. En este sentido, siguiendo a Hayek ${ }^{5}$ y a Barry ${ }^{6}$, es importante indicar que el orden social es de carácter espontáneo y consecuencia de la acción humana. Esta a su vez implica la cooperación de carácter descentralizado entre centenares de millones de individuos, cada uno tratando de buscar su propio y particular interés; y no de la voluntad humana. Este argumento debe considerarse como una idea central ha de tener en cuenta; a pesar de que el modo de hacer política pública se encuentre dominado tanto por un afán racionalista como uno constructivista. ${ }^{7}$

Asimismo, los intentos por constituir un mecanismo centralizado, es decir, monopólico, que influya positivamente en la realidad de un país no pueden pasar por alto las limitaciones implícitas que este tipo de propuestas engendran. Esto significa que debemos tener presente que muchas veces los costos y beneficios de las reglas formales de gobernanza y de su sistema de aplicación se reparten asimétricamente. Estos costos pueden recaer en un sector social específico, lo que se percibe cuando dicho sector tiene que pagarlos; pero, al mismo tiempo y de manera contraria, existen otros sectores en los que solo se concentran los beneficios. La Teoría Económica conoce a este fenómeno como la problemática de los costos concentrados y beneficios difundidos ${ }^{8}$. Cuando esta situación ocurre, es muy probable que la regla de gobernanza no sea eficaz o no se adopte. Además, debemos señalar al representar este un entorno dominado por falta de coordinación o interacción institucional positiva, los costos de las reglas pueden mostrar una tendencia inversa al ingreso de la población, lo que representa la potencial aparición de un efecto claramente discriminatorio. Esta línea de análisis cobra mayor fortaleza si entendemos que escenarios como el peruano se corresponden al de una sociedad no estructurada ${ }^{9}$.

Sin embargo, a pesar de verse afectado por una latente falta de coordinación institucional, el Perú ha comenzado a mostrar señales de cambio. Es decir, dar los primeros pasos requeridos para adquirir el estatus de sociedad transicional ${ }^{10}$

4 BLUNDELL, J. and ROBINSON, C., "La Regulación sin el Estado", : Revista Libertas, Buenos Aires: ESEADE, No 32, 2000, pp. 4-22.

5 HAYEK, F.A., Law, Legislation and Liberty, University of Chicago Press, 1978.

6 BARRY, N., “The tradition of Spontaneous Order”, Laissez-Faire, No 6, pp. 1-43, UFM Press, 1997.

7 SOLIMANO R., A., TANZI, V. y DEL SOLAR, F. S., Las termitas del Estado: ensayos sobre corrupción, transparencias, Santiago de Chile : Fondo de Cultura Económica, 2008.

8 GHERSI, S. E., "The competitive character of the Sources of Law", Revista de Instituciones, Ideas y Mercados, No 47, 2007, pp. 89-109.

9 CÁCERES, R., Institutions, Law and Cost of Transaction. Lima: Pacific University Press, 2005.

10 MÉNDEZ, R., "An introduction.... Op. cit. 
o de un entorno donde el tejido social evoluciona de modo acelerado en pos de la ansiada modernización institucional y organizacional ${ }^{11}$. En ese sentido, nos encontramos frente a un país que pretende iniciar un proceso de modernización, en el cual los poderes del Estado y, en particular, el Poder Judicial juegan un rol fundamental. No obstante, los problemas que lo constriñen son numerosos y de una enorme complejidad.

Por lo tanto, en un esfuerzo por presentar un análisis solvente, el presente documento tiene como objetivo esquematizar los aportes que la Teoría Económica ha proporcionado para analizar lo que los abogados describen por Sistema de Justicia Civil. En la primera parte, se aplican algunos de los presupuestos iniciales del análisis económico de la Justicia Civil para intentar dar una respuesta preliminar a la interrogante ¿debemos demandar? A continuación, abordamos la problemática de las externalidades vinculadas a dicho Sistema y su aparente característica de productor de un bien público, proponiendo algunos mecanismos para reducir el costo social que origina.

\section{De la Teoría Económica del Sistema de Justicia Civil}

Iniciaremos la presente sección dando respuesta a las siguientes interrogantes: ¿qué es un juez? y ¿qué es un juicio?

Desde un punto de vista jurídico, el juez es el aplicador e intérprete por excelencia, el encargado de convertir la ley en realidad. De esto se desprende claramente su responsabilidad en el funcionamiento del sistema económico y social. Sin embargo, debemos indicar que el juez, como cualquier individuo, también debe afrontar distorsiones cognitivas que podrían generar limitaciones en su actividad.

Resulta difícil que un juez permanezca neutral sobre el proceso si ha escuchado la comprometedora declaración de un testigo o leído un documento que puede definir el caso a favor de una de las partes, a pesar de que la regla legal lo obligue a declararlos inadmisibles. Entonces, para poder decidir sobre su inadmisibilidad el juez se ve obligado a estar expuesto a la misma prueba que sus ojos están prohibidos de ver. De esta manera, la perspectiva económica aplicada al estudio de las reglas, organizaciones y operadores jurídicos complementa nuestra primera elocución: el juez puede ser concebido como un agente maximizador de utilidad, encargado de asignar la titularidad ${ }^{12}$ (derecho subjetivo) a

11 NORTH, D., Institutions, Institutional Change and Economic Performance, Cambridge: Cambridge University Press, 1990.

12 Termino que incluye lo que, dentro de nuestro Sistema, conocemos como los Derechos Subjetivos, los Contratos, las Obligaciones y todas aquellas instituciones a las que se recurre jurídicamente para concretar un "intercambio económico" o cesión de Derechos de 
su uso más valioso (esto es al sujeto que demuestre lo valore más). Asimismo, se habrá de observar una extensión de esta afirmación en el principio "iura novit curia” (el juez conoce el derecho) y en el artículo VII del Título Preliminar del Código Civil Peruano.

Efectivamente, esta capacidad de maximizar la utilidad se puede percibir claramente en la actuación de un magistrado en un juicio. Esta aseveración suele ser criticada señalando que puede constituirse en un argumento a favor del soborno. Se afirma, pues, que dicho soborno también puede ser efectuado por ambas partes y que será la que realice el de mayor cuantía la que finalmente obtenga una sentencia favorable a su causa.

En realidad, consideramos que la observación del juez como un agente maximizador de utilidad no puede servir como una justificación del soborno, pues de hacerlo no sería posible concebir la obtención de un estadio de Eficiencia Social Óptimo. Por otra parte, responder la segunda pregunta implica notar que un juicio también puede ser entendido como un mecanismo institucional de asignación de titularidades alternativo al mercado, el cual es entendido como el resultado de los procesos de cooperación espontánea que se verifican continuamente en toda sociedad. De acuerdo con Bullard:

"De otra parte, cuando los costos de transacción son elevados, no se puede confiar en los mecanismos de mercado para solucionar el problema. Dado este supuesto la intervención de la Corte para reajustar el precio y la facultad de la parte que no solicita el reajuste para pedir que se resuelva el contrato, pueden conducirnos a un resultado adecuado; siempre y cuando no existan errores significativos en la decisión judicial que nos lleva a una solución ineficiente" ${ }^{\prime 3}$.

Recurrir al uso de mecanismos alternativos al mercado cobra mayor sentido si el objetivo perseguido consiste en brindar una solución satisfactoria a las partes protagonistas de un conflicto de intereses, debido a la existencia de elevados costos de transacción o costos de uso del mercado (por ejemplo, los costos que se tienen que internalizar para la solución de disputas o conflictos en este caso del mercado legal) y, por ende, la necesidad de una regla legal simple

Propiedad (entendido como Derecho de Dominio) total o parcial. Al hacer referencia de la Titularidad debemos destacar sus dos componentes característicos: la Exclusividad relacionada directamente con la variable escasez, fundamental para que el individuo pueda efectuar una adecuada asignación de valor dado que: Escasez + Utilidad = Valor; y la Enajenabilidad. Por ejemplo, un matrimonio no puede ser considerado como una titularidad pues sus integrantes en sí, no pueden ser objeto de enajenación.

13 BUllard G., A., Estudios de Análisis Económico del Derecho, Lima: Ara Editores, 1996, p. 228. 
y clara ${ }^{14}$. Surgirá entonces el "Problema de la Titularidad", el cual consiste en un problema legal que aparece toda vez que, dentro de un Estado, se presentan conflictos de intereses entre dos o más personas, o dos más grupos; y es el Estado quien debe decidir a qué parte favorecer dado que este conjunto a su vez ampara sus pretensiones en titularidades (derechos subjetivos) presentados de manera contrapuesta. Un ejemplo clásico de esto sería el conflicto en la titularidad para hacer ruido vs la titularidad para gozar del silencio). Asimismo, siguiendo a Calabresi y Melamed $^{15}$, las razones para decidir otorgar a las personas una titularidad son:

a. Eficiencia Económica. Asignar recursos al mínimo coste de manera que el bienestar de un individuo no podrá aumentar sin provocar, por consiguiente, una disminución del bienestar de los otros miembros de la sociedad.

b. Objetivos Distributivos. Implican distribuir o repartirla riqueza misma o ciertos bienes específicos.

c. Otras Razones de Justicia. Razones finales para la elección de una titularidad inicial que implican consideraciones morales y emotivas complementarias a los criterios de eficiencia y distribución de los recursos.

Además, debemos señalar que, en el caso específico de la Corte Suprema, cuyas decisiones pueden sentar jurisprudencia normativa al ser estas tomadas como pautas o imitadas por otros magistrados tornarán cada vez más previsibles las resoluciones judiciales. Lo cual generará incentivos para recurrir al Sistema Judicial pues será más simple predecir el resultado de una disputa. De acuerdo con Diez Canseco Núñez y Pasquel Rodríguez:

"La Corte Suprema debe determinar de manera indubitable cómo se interpretan las normas jurídicas en casos concretos. Tiene la capacidad de implementar "precedentes de observancia obligatoria" para todos los órganos jurisdiccionales, pues todas las sentencias de la Corte Suprema generan Stare Decisis (estar a lo decidido). La ventajas de este mecanismo pueden resumirse En: a. Celeridad Procesal: Se contribuye a desincentivar la presentación de demandas cuya posibilidad de éxito no sea razonable, reduciendo además el trabajo de los jueces y la necesidad de entrar en complejas y costosas discusiones jurídicas; b. Mayor Control de Corrupción: Al limitarse la discrecionalidad judicial en la interpretación de las normas jurídicas, contribuyendo al establecimiento de estándares objetivos que permiten determinar cuándo

14 EPSTEIN. R. A., Principios para una sociedad libre (traducción del libro Principles for a Free Society. Reconciling Individual Liberty with the Common Good), Lima: Universidad Peruana de Ciencias Aplicadas Editores, 2003.

15 CAlabReSI, G. and MELAMED, A. D., "Property Rules, Liability Rules and Inalienability: One View of the Cathedral", Harvard Law Review, Vol. 85, 1972, p. 108. 
la interpretación judicial se aleja del espíritu de la norma y al reducirse la posibilidad de un particular para intentar corromper a un juez; c. Mayor Credibilidad Institucional: Al obtenerse claros lineamientos jurisprudenciales se contribuye en la generación de mayor confianza en el Poder Judicial, brindando una imagen de transparencia e imparcialidad, reduciendo además la problemática de las sentencias contradictorias. Al generarse mayor credibilidad institucional se generan incentivos para atraer a profesionales más capacitados y mejoras en las condiciones de trabajo de los magistrados (circulo virtuoso) lo que se reflejará en la calidad de las resoluciones y del servicio brindado a la ciudadanía; d. Promoción de la Inversión: Al tenerse criterios claros de la aplicación de la ley en casos concretos se potencia la seguridad jurídica, lo que se refleja en un mejor clima para la inversión pues se reduce el riesgo país; e. Revalorización de la Judicatura: Al brindarse un servicio de calidad, se contribuye en cambiar la percepción de la ciudadanía de la figura del Juez como un agente corrupto. Este factor además incide en la capacidad de negociación del Poder Judicial frente a los otros poderes del Estado a los cuales se encuentra supeditado. Los jueces integrantes de un Poder Judicial independiente serán en menor medida objeto de las frecuentes presiones (de integrantes del ejecutivo y del legislativo) para influir en sus decisiones. No obstante no se deberá confundir la autonomía jurisdiccional con el (inaceptable) poder ilimitado de la jurisdicción. Los límites institucionales al poder de los magistrados, al igual que el de las distintas instancias jerárquicas y jurisdiccionales deben ser claros. Con la finalidad de potenciar el Stare Decisis muchas de las voces que apuestan por una Reforma Judicial piden la creación de un sistema de publicidad(a bajo costo) de los precedentes, el cual permitirá hacer de público conocimiento la adopción cada precedente. Los mecanismos de publicidad estarán orientados a jueces, secretarios, técnicos, usuarios, etc ${ }^{16}$."

Lo expuesto constituye, en realidad, otra forma de entender el factor Previsibilidad, el cual contribuye en disminuir el costo de oportunidad del uso del sistema de justicia y los costos de transacción. Igualmente, podemos afirmar que la doctrina jurídica reconoce la vigencia de este factor, cuyo postulado se refleja en el artículo 400 del Código Procesal Civil que, a la letra, establece:

"Cuando una de las Sala lo solicite, en atención a la naturaleza de la decisión tomar en un caso concreto, se reunirán los vocales en sal Plena para discutirlo y resolverlo. La decisión que se tome en mayoría absoluta de los asistentes al Pleno constituye doctrina jurisprudencial y vincula a los órganos jurisdiccio-

16 DIEZ CANSECO NÚÑEZ, L. y PASQUEL RODRÍGUEZ, E., "Stare decisis, intercambios comerciales y predictibilidad: una propuesta para enfrentar la reforma del Poder Judicial". Revista de Economía y Derecho, No 2. Lima: Universidad Peruana de Ciencias Aplicadas, 2004. 
nales del Estado, hasta que sea modificada por otro pleno casatorio. Si los Abogados hubieran informado oralmente a la vista de la causa, serán citados para el pleno casatorio. El pleno casatorio será obligatorio cundo se conozca que otra Sala está interpretando o aplicando una norma en un sentido determinado. El texto integro de todas las sentencias casatorias y las resoluciones que declaran improcedente el recurso, se publican obligatoriamente en el diario oficial, aunque no establezcan doctrina jurisprudencial. La publicación se hace dentro de los sesenta días de expedidas, bajo responsabilidad".

Por otra parte, es conocido y aceptado que en el Perú el Sistema de Justicia Civil se caracteriza por una clara influencia de la tradición romano-germánica, en lo referente a su desarrollo. Entre las diferencias que podemos encontrar entre su sistema legal y otros (por ejemplo, el anglosajón) podemos señalar aquella que asigna la mayor parte de los costos contables del proceso ${ }^{17}$ al perdedor (en el sistema anglosajón casi siempre son las partes las que asumen estos costos de carácter pecuniario).

Sin embargo, al ser un proceso un mecanismo alternativo al mercado, en el que se requerirá de un elemento exógeno "designado"18 por el aparato estatal a las partes (juez) para la solución del conflicto, se crea el riesgo de errores aplicativos o dilataciones, cuyo origen radica muchas veces en problemas de asimetría informativa. Esta última como la consecuencia de la manipulación de la información sobre los hechos originarios de la disputa que cada una de las partes conoce. Situación que se condice con el elemento racional de la conducta, pero que puede caer dentro de lo no-razonable ${ }^{19}$ si realizamos un análisis plenamente jurídico.

Uno de los primeros aportes del estudio del comportamiento regulado por un sistema judicial examina, entonces, cómo las partes intervinientes en un litigio responderán a las restricciones que el proceso les impone ${ }^{20}$.

17 Los costos "contables" del proceso hacen referencia a los honorarios del abogado, pagos administrativos, etc.

18 Salvo circunstancias especiales de "competencia facultativa", la cual esta prevista en los artículos 14 y 24 del CPC, el demandante no puede "escoger" al juez.

19 Las diferencias entre razonabilidad y racionalidad son tema de permanente debate.Se puede afirmar, por ejemplo y de forma preliminar, que el comportamiento racional consiste en el intento por alcanzar objetivos a través de medios eficientes. Si los medios son ineficientes o contradictorios se presenta la irracionalidad. No obstante esta definición puede dar cabida a comportamientos que pueden ser catalogados de arbitrarios, antisociales e incluso inmorales. Por su parte, un agente razonable es relacionado con los valores compartidos por el grupo al que pertenece.

20 No obstante generalmente los estudios de la conducta regulada por el sistema legal dan por sentado la estructura de las reglas procedimentales, penas, etc., es decir los consideran un factor Ceteri Paríbus. 
1. Mayor duración del proceso $=$ Mayores costos contables (asumidos por las partes y redistribuidos al final a través de la sentencia) y Mayores Costos administrativos del Sistema (mayor Costo Social).

2.

$$
\begin{aligned}
& +\mathbf{T}-\mathbf{I}=+\mathbf{C t} \\
& +\mathbf{T}-\mathbf{I}=+\mathbf{C o}
\end{aligned}
$$

Las expresiones desarrolladas nos sirven para indicar gráficamente que, a mayor tiempo $(+\mathrm{T})$ y menor información $(-\mathrm{I})$, se incrementarán tanto los Costos de Transacción (+ Ct) como el Costo de Oportunidad (Co) del proceso.

De lo expuesto líneas arriba, se desprende que sólo una solución obtenida como resultado de una negociación permitirá a las partes en conflicto alcanzar una situación que los economistas suelen identificar con el Criterio de Pareto (b). Situación en la cual se produce la mejora de un individuo sin afectar el bienestar individual de otros, que como efecto produce una mejora del bienestar social. Y, en menor proporción con el Óptimo de Pareto (a), situación en la cual se arribará al grado máximo de eficiencia, en donde el bienestar de un individuo no podrá aumentar sin, por consiguiente, provocar una disminución del bienestar de otros miembros de la sociedad. De no producirse una salida a la disputa por medio de un arreglo entre las partes, la solución a la que se arribe una vez concluido el proceso (sentencia del magistrado) será consistente con el Criterio (distributivo) de Kaldor y Hicks/Scitovsky (c). Donde se producirá la mejora de una de las partes en desmedro de la otra, pero de forma que los beneficios (de la parte X) superen las pérdidas (de la parte Y). Lo que puede permitir, además, que estos beneficios (en X) compensen las perdidas producidas (en Y) o que inclusive permitan un desplazamiento ascendente (de Y).

a. No es posible que $X$ o que $Y$ mejoren sin por consiguiente se ocasione un daño a J,U,S,T,I,C,I;A (que se corresponden a los demás agentes conformantes de la sociedad): Óptimo de Pareto.

b. Mejoría de X no afecta a Y: Criterio de Pareto.

c. Mejoría de X supera perdida de $Y$, lo que puede permitir compensar a $Y o$ mejorar su situación a un estadio superior de bienestar: Criterio de Kaldor y Hicks/Scitovsky.

Estas tres situaciones descritas son concebidas por la Ciencia Económica como estadíos de eficiencia que deben ser enfocados como los objetivos a alcanzar a fin de lograr una mejora en el bienestar general de la sociedad.

\section{3. ¿DEBEMOS DEMANDAR?}

Como se ha expuesto anteriormente, hacer uso del sistema legal implica asumir un costo. Este puede fluctuar en dirección ascendente o descendente, según 
nuestras estimaciones individuales (subjetivas). Aún así, siempre, será útil el poder realizar un análisis cualitativamente formal de los costos contables aproximados en los que se deberá incurrir con el fin de obtener el resultado esperado (Re en adelante), es decir, ganar la demanda. Estos se pueden expresar a través de la siguiente representación:

\section{$\mathrm{Cl} \times \mathrm{T}<\operatorname{Re}$}

Donde $\mathrm{Cl}$ representa los costos en que se incurre por el concepto de presentar la demanda, buscar y contratar un abogado, acopio de medios probatorios, monitoreo del accionar del abogado, etc. Y, donde $T$ representa la duración del proceso que es un factor que ocasiona que $\mathrm{Cl}$ sufra un incremento $\mathrm{Re}$.

Esta simple formulación nos permite entender fácilmente que, solo si $R e$ es mayor, será conveniente iniciar un proceso. Asimismo, partiendo de esta misma formulación es posible deducir que en caso de perder en primera instancia (o no obtener una sentencia satisfactoria), solo si Re representa un valor más alto que el del costo a incurrirse será adecuado continuar con la reclamación legal $(C l \times T) 2$.

$$
\mathbf{C l} \times \mathbf{T}+(\mathbf{C l} \times \mathbf{T}) 2<\mathbf{R e}
$$

Por el contrario, en caso el individuo observe que de su análisis se desprenda la siguiente expresión:

$$
\mathrm{Cl} \times \mathrm{T}+(\mathrm{Cl} \times \mathrm{T}) 2>\operatorname{Re}
$$

Podríamos inferir que su naturaleza racional (Becker, 1976) lo puede llevar a dejar de lado una solución al conflicto por la vía judicial. ${ }^{21}$ Según el modelo propuesto, los individuos evaluarán los acontecimientos o los conjuntos de acontecimientos desde el punto de vista impacto en su riqueza material. No obstante, aunque los individuos suelen sopesar cada uno de los acontecimientos por separado y conceder mucha menos importancia a la ganancia que a la pérdida (Sunstein, 2004), esta no ha sido la regla de partida en la formulaciones precedentes.

\section{Proceso y Sistema legal: externalidades}

Hasta aquí, hemos hablado de los costos en que se puede incurrir en caso se desee iniciar un proceso legal y de lo beneficioso que puede resultar una solución alternativa. Como se puede observar, hemos partido de un modelo en el cual se han dejado de lado numerosas variables que se podrían presentar en el transcurso de un proceso.

${ }_{21}^{21}$ Partimos del supuesto general que los individuos son adversos o renuentes al riesgo. 
La aparición de estos advenimientos puede resultar ser tanto negativa como positiva para la obtención del resultado esperado. Además, estos sucesos pueden tener su origen tanto en el sistema mismo, como en su mecánica, sus postulados y principios, como en la parte aplicativa y administrativa. Pueden, además, ser consecuencia de una parte objetiva (la norma) y una subjetiva (el operador jurídico). Ciertamente, a ese conjunto de situaciones que se presentan de manera imprevista y manifestándose siempre entre dos agentes, los economistas suelen denominarlas por el nombre de externalidades. Estas pueden ser de dos tipos:

- Negativas, cuando su aparición no favorece, en el caso del desarrollo de un proceso, a ninguna de las partes debidamente legitimadas ante el juez.

- Positivas, si su presencia acarrea como consecuencia que una de las partes que participa en el proceso se vea favorecida.

No está demás señalar que, en la realidad, no se verificará jamás la existencia de un proceso libre de externalidades. Imaginemos, por ejemplo, dos situaciones que se suelen repetir y afectar a los agentes que hacen uso de la provisión de servicios prestada por el sistema legal peruano: una huelga de trabajadores del poder judicial, cansados de percibir sueldos muchas veces irrisorios; y un abogado incompetente que no observa una conducta profesional adecuada requerida por todo querellante, pues su accionar permite a la contraparte hacer prevalecer sus exigencias ante el juez.

Como se menciona líneas arriba, otro generador de externalidades pueden ser las normas (leyes). Debido a que muchas son resultado de antiguas construcciones teóricas, divorciadas de nuestra realidad. Estas, principalmente en el campo procedimental, pueden devenir por sí solas en obstáculos (barreras legales) que los individuos que consideren una solución por la vía judicial deberán de sortear. Esto no se condice con una de las funciones que la teoría económica destaca y que debe de cumplir la ley, que es contribuir con nivel adecuado de Previsibilidad (factor opuesto al de Imprevisibilidad que desarrollaremos más adelante). Factor que, conjuntamente con su característica Oponibilidad, la cual deriva del monopolio de la fuerza por parte del Estado, permiten reducir los costos de transacción $(\mathrm{Ct})$.

Es importante señalar que la ley no es más que un instrumento (carácter de Instrumentalidad de la ley) y no un fin en sí mismo, desarrollado con una clara finalidad supletoria (en lo que respecta al Derecho Civil) a la voluntad de los individuos.

De lo expuesto se desprende, claramente, que el legislador no considera que las normas legales crean precios implícitos (sombra) para tipos diferentes de 
conducta. Esto puede ser considerado como una de los factores que inciden en la proliferación de propuestas legales (ver gráfico 1) sin mayor sustentación técnica. Y, además, que las respuestas a estos "precios" pueden ser examinadas de la misma forma en que se examina el comportamiento de la demanda (consumidores, usuarios, etc.) sobre los precios explícitos de cualquier bien o servicio.

Gráfico 1: Proyectos de Ley presentados (PL) en números 2007.

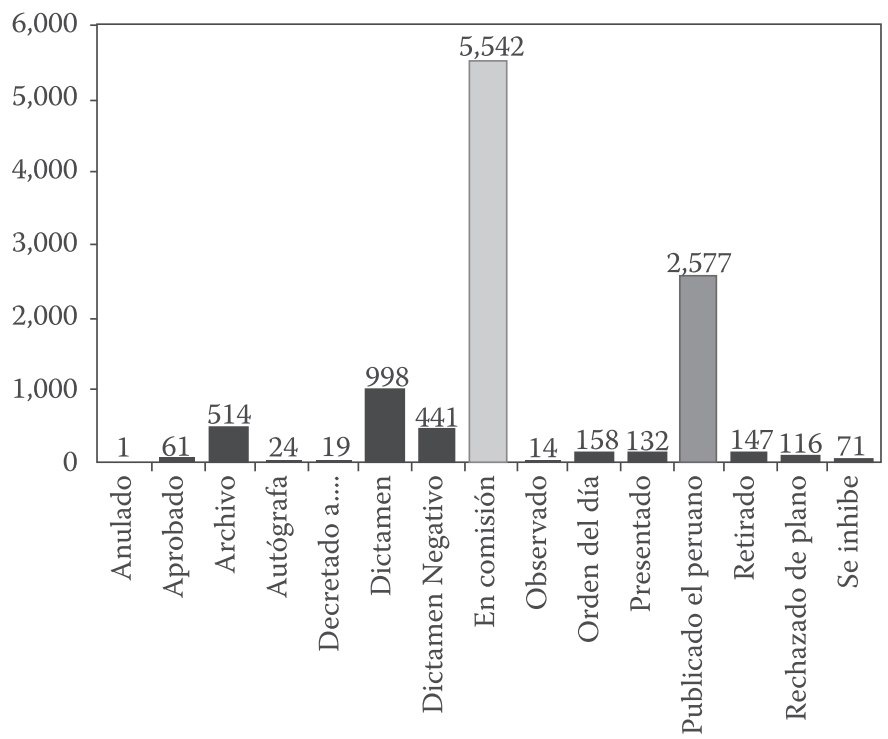

Fuente: Instituto Peruano de Economía - Reflexión Democrática.

Por su parte, la existencia de un sistema proveedor de justicia -claramente ineficiente- contribuirá como un factor más por el lado de los costos que los individuos deberán de tener en cuenta antes de efectuar un proceso de elección (iniciar o no la disputa legal) y la correspondiente asignación de recursos son el fin de satisfacer sus necesidades (de justicia).

La aparición de externalidades tiene como consecuencia la aparición de un factor adicional que debemos contemplar en nuestro análisis: la Imprevisibilidad (I). Este factor suele actuar como una función creciente en el costo pues, el no poder determinar ex-ante el posible resultado de la disputa, hará que los individuos lo piensen dos veces antes de iniciar un proceso. Esto último se puede expresar mediante la siguiente formulación:

\section{$\mathrm{Cl} \times \mathrm{T} \times \mathrm{I}>\mathbf{R e}$}


Pero el problema radica en que las externalidades se presenten en el proceso de manera ex-post, lo cual, al no poder ser previsto por el querellante, que muchas veces se guía por la expectativa de obtener un resultado favorable (Re), deberá ser asumido. Es necesario recordar que los individuos suelen sobreestimar la posibilidad de obtener resultados positivos y, a su vez, a minimizar el riesgo de pérdida o fracaso ${ }^{22}$.

\section{5. ¿ES LA JUSTICIA CIVIL UN BIEN PÚBLICO?}

El Sistema de Justicia Civil es considerado por muchos como un proveedor del bien público "justicia civil", lo que se convierte en un factor que impide lograr asignaciones eficientes a través del mercado. Un bien público puro es aquel que tiene dos propiedades específicas:

- No genera rivalidad. Lo que significa que su utilización por parte de una persona no reduce la cantidad del bien para otras.

- No genera capacidad de exclusión. Lo que significa que es imposible o prohibitivo, en término de costos, impedir que lo utilicen las personas que no lo pagan.

No obstante, aunque pueda parecer que los agentes privados, debido a los factores anteriormente señalados, no estarán dispuestos a proveer a la sociedad de bienes públicos; debemos refutar este supuesto. Los agentes privados suelen mostrar un gran ingenio para descubrir y desarrollar mecanismos para ofrecer bienes públicos ${ }^{23}$. Ejemplos de esta afirmación son el Sistema Arbitral y la Conciliación Extrajudicial que, pese a sus probables falencias, son mecanismos que pueden contribuir en reducir el Costo Social.

Incluso podemos observar que las limitaciones de estos sistemas no tienen su origen en sí mismos, sino en el pobre desarrollo institucional, que no les proporciona un marco adecuado para efectuar su funcionamiento. No obstante, es sencillo percibir que la justicia civil es considerada como un bien de características públicas. Es decir, un bien que, una vez producido, beneficia a un

22 SUNSTEIN, C. R., "Análisis Conductual del Derecho”, Revista Advocatus Nueva Época, Lima: Advocatus Editores, No 9, 2003, pp. 57-74.

23 BENEGAS-LYNCH, A., "Bienes públicos, externalida- des y los free-riders: el argumento reconsiderado", Estudios Públicos, Santiago de Chile: CEP Editores, No 71, 1998, pp. 203-218; BAYLY LETTS, A. y PASQUEL RODRÍGUEZ, E., “¿Quién dijo que en Salem hubo brujas? La privatización del servicio de justicia: rompiendo el mito de la justicia estatal", Lima: Themis Revista de Derecho Segunda Época, No 46, 2003, pp. 315-346. 
amplio conjunto de consumidores (litigantes) hayan o no pagado por él, pues la incorporación de un consumidor adicional no implicaría mayores costos.

Concebir de esa forma a la justicia civil resulta erróneo, pues implica afirmar que el mercado per se no constituye un mecanismo relativamente idóneo para su provisión. Esto debido a que las personas carecerían de incentivos para manifestar una mínima disposición a asumir los costos explícitos generados. Lo cual equivale a afirmar que los individuos esperarán que sean otros los que asuman el costo pecuniario para obtener, de esa forma, un beneficio (conducta free rider).

En realidad, la justicia civil es un bien que claramente genera exclusión. ${ }^{24}$ Pues, si fuese un bien público, su producción asociada a un sistema de mercado podría resultar poco favorable. Y, desde una perspectiva convencional, habría menos "justicia" de la socialmente necesaria.

Asimismo, observar en la justicia civil como bien de carácter público puede contribuir en el análisis positivo del "modelo predominante". Nos referimos a un mecanismo centralizado destinado a proveer el servicio de justicia bajo la supervisión de funcionarios remunerados por el Estado, financiado con cargo a rentas (círculo vicioso) y con barreras ocultas de acceso. ${ }^{25}$

Un estudio no muy profundo del sistema -específicamente de la composición del proceso y de las manifestaciones conductuales de los agentes intervinientes- permite demostrar que no es cierto que incorporar un nuevo participante (querellante) carezca de $\operatorname{costos}^{26}$, o que no exista rivalidad por acceder al sistema, o que no sea posible una exclusión costo-eficiente. Ninguna de estas características propias de un bien público está presente en la justicia civil. Este "producto" se constituye como un claro ejemplo de un bien privado cuyos beneficios (aunque no siempre la totalidad de sus costos) son internalizados por los participantes directos o indirectos.

Proporcionar un bien como la justicia civil de aparente carácter público al potencial consumidor, en realidad, significa aceptar el establecimiento de incentivos perversos para producir un resultado socialmente peligroso. Así, si el consumidor no asuma la totalidad de los costos que genera, se deberá establecer un "subsidio" a ese bien, lo que significa que se acrecentará artificialmente el

24 PEÑA C. G., Correa S., J. y Vargas, J. E., "El rol del Estado y el mercado en la justicia", Cuadernos de Análisis Jurídico, Santiago de Chile: Universidad Diego Portales y Fundación Ford, 2001.

25 Que no resulta consistente con un eficiente sistema de precios.

26 No obstante los costos hundidos del sistema el costo de oportunidad del mismo permanece latente. 
nivel de bienestar asociado al proceso, que equivale a una practica discriminatoria con la cual los costos se difundirían en la sociedad y los beneficios se concentrarían en ciertos "demandantes". Pero lo pernicioso radica, también, en que los individuos tendrán incentivos para litigar en una proporción claramente superior a la adecuada desde el punto de vista de la Eficiencia Social. ${ }^{27}$

Aunque los costos explícitos e implícitos que están asociados al litigio sean superiores al beneficio que con él se obtiene ${ }^{28}$ (como se demuestra claramente líneas arriba), los individuos seguirán adoptando la opción de demandar ${ }^{29}$. Lo cual, al constituirse en una clara divergencia entre los costos sociales y privados del proceso, generará la aparición de externalidades. Pues al ser la justicia civil un bien rival, cada acción judicial, generará efectos no contratados (externalidades) sobre el conjunto de la sociedad, que no serán internalizados por el querellante.

No obstante, si partimos del supuesto de un sistema que funciona, debemos contemplar la posibilidad de que se produzcan beneficios que se extenderán más allá de los participantes del mismo. Es este supuesto el que se constituye como la dimensión pública del Sistema de Justicia Civil pues, con la existencia de esos beneficios, el óptimo privado en la provisión del bien se diferencia del óptimo social. Igualmente, en una situación como esta, se puede observar claramente que existirá una parte del beneficio de demandar que no recaerá en el litigante. Por lo tanto, es necesario mantener como guía la noción de que un sistema eficiente e independiente de Justicia Civil (contexto inverso a la realidad actual tal como lo ilustra el gráfico 2), asunciones respaldadas teóricamente y contenidas en las reglas que organizan la práctica o ejercicio de la judicatura, debe contribuir en la disminución de los costos de transacción y evitar la generación de externalidades negativas o la introducción de efectos perversos.

$27 \quad$ No obstante partamos de un contexto de elevados costos de transacción y del análisis de la conducta de un individuo renuente al riesgo; esta situación, sin lugar a dudas, ocasionará que el sistema colapse.

28 Lo que puede dar a entender, para algunos, la prevalencia de una conducta irracional y, por ende, la excusa necesaria para justificar la ansiada y perversa intervención estatal.

29 Siguiendo a SUNSTEIN, C. R., "Análisis Conductual del Derecho", Revista Advocatus Nueva Época, Lima: Advocatus Editores, No 9, 2003, pp. 57-74., así como a MOSTERIN, J., "Herencia genética y transmisión cultural", Evolución, vol. 7, no 12, 2012, pp. 71-86., podemos inferir que percepción no es igual a realidad. La mente humana tiende a buscar "patrones" aún si no los hay. Además, las creencias se forman con o sin evidencia. El sistema de creencias resultante sirve como modelo: a.- Positivo: Predicciones; y b.- Normativo: Juicio de Valor. Este modelo puede ser homogéneo o muy diverso. 
Gráfico 2. Nivel de Independencia Judicial.

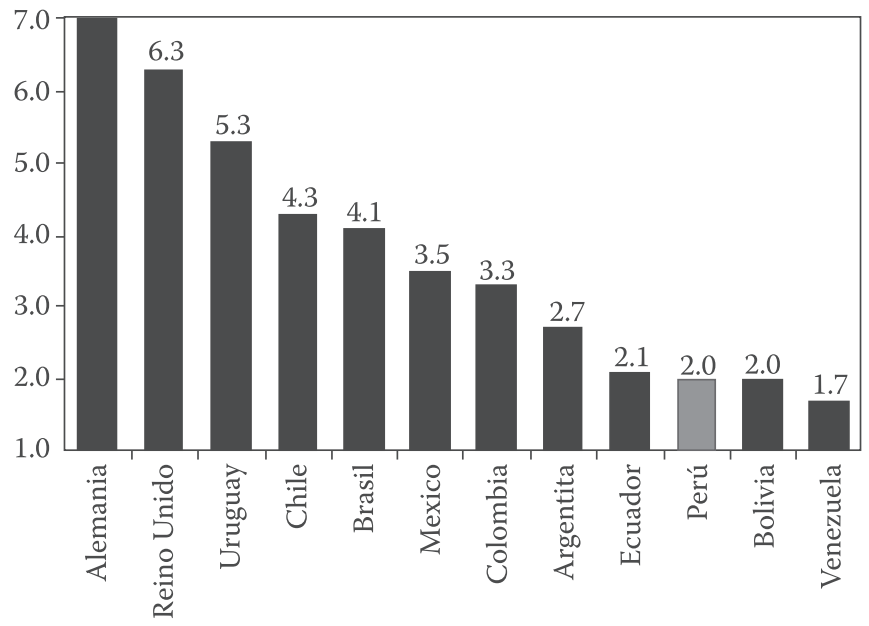

Fuente: World Economic Forum 2002.

Frente a este tipo de inconvenientes y solo en supuestos específicos, la teoría convencional concibe la posibilidad de optar por una participación más expresa del Estado, a través del financiamiento de esa proporción de los beneficios con cargo a rentas de modo que sea viable alcanzar el óptimo social ${ }^{30}$.

\section{REPENSANDO EL SISTEMA}

La reforma del sistema de justicia no se obtendrá sin una transformación del marco institucional y de la imperante concepción de lo que los agentes especializados conocen y entienden por derecho. El cambio de esta concepción es importante en el diseño de cualquier modelo futuro de modernización institucional si se entiende que en el contexto jurídico peruano, el concepto derecho está claramente inspirado en una forma muy peculiar de positivismo jurídico que otorga mandato a una ley como regla centralizada (taxis) introducida por un planificador central (legislador). Esto último, en lugar de que la legislación se inspire en la norma espontáneamente surgida o fruto de un proceso inacabable de ensayo y error (cosmos).

La imperante visión positivista debe ser corregida en la medida que genere espacios para la prevalencia de reglas que afectan a la sociedad, como el uso

30 LANDSBURG, S. E., El economista en pijama (traducción de Alejandro Tiscornia), Buenos Aires: Editorial Atlántida, 1995. 
arbitrario del criterio de conciencia y la aceptación tácita de su compra-venta. Esto representa un costo que además, viene acompañado por aquel que producen las lagunas jurisdiccionales, a pesar de la existencia de los celebrados métodos de integración. Estas, en gran medida, son la consecuencia de la debilidad institucional (Levitsky et al, 2010) y la aún limitada experiencia jurisprudencial, entendida como un bien de capital.

Por otra parte, en las tres últimas décadas, la interrelación y la "división del trabajo" entre el sector Público y Privado, y entre el Estado y el Mercado ${ }^{31}$ han sufrido profundas transformaciones. No obstante, los problemas aún vigentes no sólo se mantienen generando, desde fines de la década del ochenta, una grave crisis de gobernabilidad ${ }^{32}$. Una característica central de este proceso ha sido el colapso de los poderes del Estado, en particular del Poder Judicial.

Si bien en los últimos años se ha intentado efectuar diversas acciones con el objetivo de incrementar la eficiencia de la actividad de este poder del Estado, queda claro que este sigue presentando una estructura que le impide cumplir con sus objetivos básicos. En este sentido, el Poder Judicial y, en particular, el Sistema de Justicia Civil, muestran aún ineficiencias, desarticulaciones, métodos y vacíos que restringen severamente su capacidad para lograr objetivos y asignar recursos apropiadamente. Tampoco cuentan con una conciencia clara de su rol ni con mecanismos competitivos de formación de personal.

Cuadro 1: Magistrados del Poder Judicial a nivel Nacional, según condición (1997-2002).

\begin{tabular}{lccc}
\hline $\begin{array}{c}\text { Elaboración: } \\
\text { Proyecto Justicia Viva }\end{array}$ & $\begin{array}{c}\text { Agosto } \\
\text { de 1997 }\end{array}$ & $\begin{array}{c}\text { Mayo } \\
\text { de 1999 }\end{array}$ & $\begin{array}{c}\text { Agosto } \\
\text { del 2002 }\end{array}$ \\
\hline Total de magistrados & 1445 & 1512 & 1525 \\
\hline Provisionales y suplentes & 1053 & 1188 & 653 \\
\hline Titulares & 392 & 324 & 872 \\
\hline \% de titulares & $27 \%$ & $21 \%$ & $57 \%$ \\
\hline
\end{tabular}

Fuente: Poder Judicial del Perú, revista Poder Judicial, Lima, setiembre-octubre de 2010, p.3; Instituto Apoyo, Reforma del poder judicial, Lima 2010, p. 22; Consejo Nacional de la Magistratura, Informe de la Secretaría Técnica de Selección y Nombramiento, agosto del 2002.

31 CÓRDOVA, D., "La nueva economía institucional y el análisis del subdesarrollo en América Latina”, Revista de Economía y Derecho, No 2. Lima: Universidad Peruana de Ciencias Aplicadas, 2004, pp. 7-23.

32 Cfr. SARDÓN, J. L., La Constitución Incompleta, Lima: Instituto Apoyo, 1999.; SIEGAN, B. H., Reforma Constitucional, Lima: Centro de Investigación y Estudios Legales, 1993. 
Por este motivo, se genera un sentimiento de desconfianza de la ciudadanía hacia este poder del Estado, lo que claramente incide en un debilitamiento de la confianza interpersonal. Desde un punto de vista sociológico, esta es una variable relevante que toma en su conjunto al sistema institucional y organizacional en función a su nivel de eficacia y legitimidad. Por otra parte, desde un punto de vista económico, nos encontramos frente a un factor que en el largo plazo incidirá negativamente en la formación de un sólido y competitivo capital social, un elemento esencial de toda sociedad que apunte a constituirse como un tejido social estructurado ${ }^{33}$.

Gráfico 3: Comparación de niveles de Confianza Interpersonal por país (Latinoamérica).

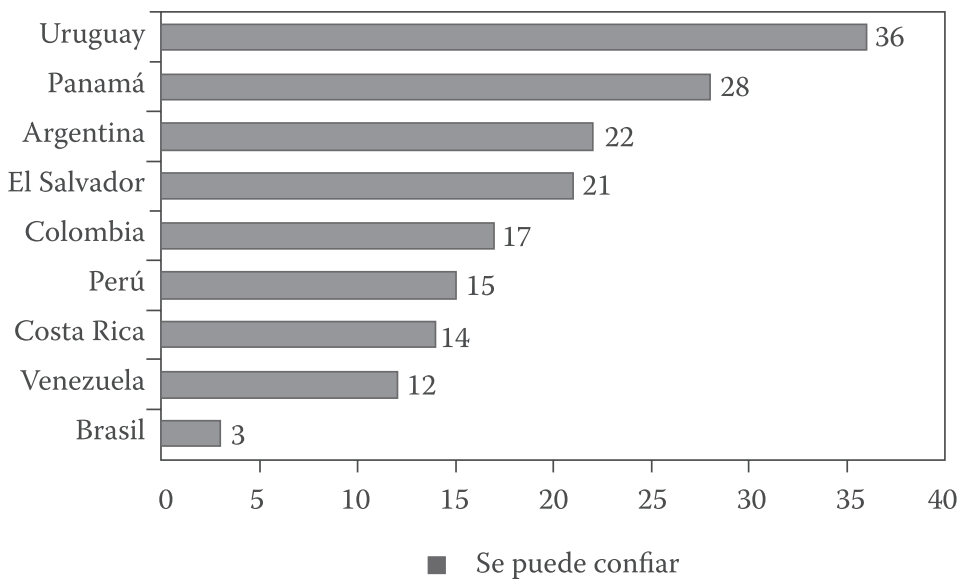

El gráfico 3 muestra que se han consolidado los datos del Latino Barómetro para el período 1996-2001(en realidad son cinco años porque en 1999 y el 2001 la encuesta fue la misma). El Perú, con una confianza interpersonal de alrededor del 15\%, sólo se encuentra por encima de Brasil, Venezuela y Costa Rica. Mientras Uruguay (36\%) es el país que en Latinoamérica presenta el mayor nivel de confianza interpersonal seguido por Panamá y Argentina. Asimismo, si nos concentramos en la tendencia de estos estudios no observaremos mayores variaciones con relación a la ubicación del Perú en este ranking.

33 MÉNDEZ, R., "An introduction.... Op. cit. 
Gráfico 4: Variaciones de los niveles de Confianza Interpersonal en la región de América Latina (1996-2002).

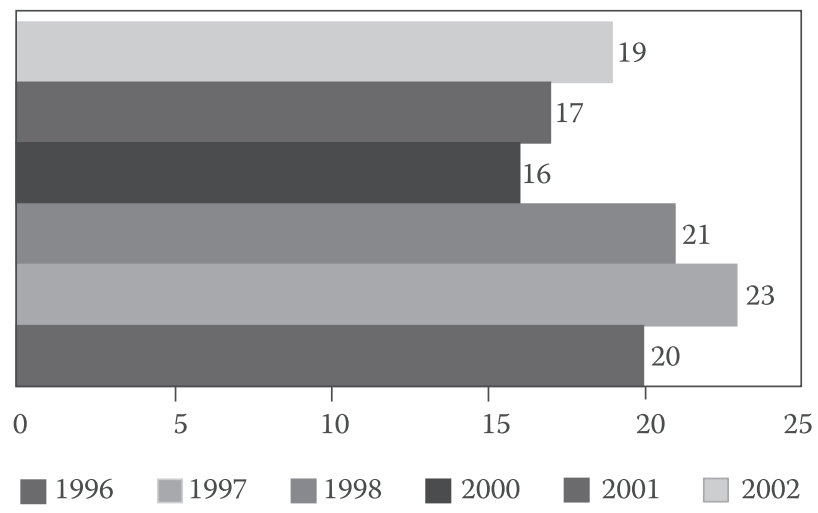

Cuadro 2: Nivel de Confianza Interpersonal.

\begin{tabular}{lc}
\hline \multicolumn{1}{c}{ Regiones } & Nivel de Confianza Interpersonal \\
\hline América Latina & $20 \%$ \\
\hline Europa Occidental & $50 \%$ \\
\hline EEUU y Canadá & $50 \%$ \\
\hline Japón & $43 \%$ \\
\hline
\end{tabular}

Fuente: BID/ World Values Survey (1990-1993).

Por otra parte, el gráfico 4 nos muestran que, a nivel comparado y basándonos en los datos del BID y el WVS, el nivel de confianza interpersonal es considerablemente más elevado en la mayor parte de los países de Europa occidental, al igual que en Estados Unidos, Canadá y Japón. En promedio, cerca del $50 \%$ de los entrevistados en los países de Europa occidental aseguran que pueden confiar en otros. Una cifra similar nos ofrecen los Estados Unidos y Canadá mientras que países como Japón muestran un porcentaje relativamente menor (43\%).

Sobre este punto, consideramos necesario destacar que una de las características más saltantes de nuestro país y de la mayoría de países en desarrollo es que la gran mayoría de sus reglas no se cumplen. Las razones fundamentales de dicho incumplimiento no son la rebeldía o el intentar entorpecer a los gobiernos de turno. Por el contrario, como podemos constatar el texto de 
las reglas formales (leyes), quienes las elaboran y quienes hacen operativo el sistema cometen típicamente dos errores. Por un lado, presumen que los incentivos privados y colectivos no importan; y, por el otro, suponen (ceteri paríbus) que las instituciones y organizaciones que están involucradas en el efectivo cumplimiento de la legislación funcionan apropiadamente. Es decir, libres del fenómeno de la corrupción, asunción que para en el Perú es refutada a través de la introducción de consolidados como el expresado por el cuadro 4 y a través de la aplicación de las contribuciones científicas de autores como Blind $^{34}$, Solimano ${ }^{35}$ y Ghersi ${ }^{36}$.

Cuadro 4: Instituciones y Nivel de Corrupción.

\begin{tabular}{lll}
\hline \multicolumn{1}{c}{ Países } & \multicolumn{1}{c}{ Instituciones } & \multicolumn{1}{c}{ Corrupción } \\
\hline Argentina & Libre & Alta Corrupción \\
\hline Brasil & Mayormente Libre & Alta Corrupción \\
\hline Chile (13) & Libre & Baja Corrupción \\
\hline Colombia & Mayormente Libre & Alta Corrupción \\
\hline Ecuador & Mayormente Libre & Alta Corrupción \\
\hline México & Mayormente Libre & Alta Corrupción \\
\hline Perú(58) & Mayormente Libre & Alta Corrupción \\
\hline Venezuela & Mayormente Libre & Alta Corrupción \\
\hline
\end{tabular}

Fuente: The Heritage Foundation, USA.

Consideramos que en aplicación del enfoque de racionalidad económica (tradicional) -tal como lo describe Frank ${ }^{37}$ - la asunción del cumplimiento sin tomar ventaja es un equivoco. Esto es así, pus si los agentes de una sociedad ven una posibilidad de mayores beneficios incumpliendo las reglas, por qué asumir que no lo van a hacer. Con mayor razón, si los organismos que conforman el sistema responsable de supervisar su cumplimiento son torpes e ineficientes al efectuar su labor o, peor aún, si son los mayores infractores. Es posible, entonces, afirmar que los individuos actuando como agentes racionales cumplirán con

34 BLIND PK., Building Trust in Government in the Twenty-first Century: Review of Literature and Emerging Issues, Austria: UNDESA, 2006.

35 SOlimANO R., A., TANZI, V. y DEL SOLAR, F. S., Las termitas del Estado... Op. cit.

36 GHERSI SILVA, E., "El capitalismo antidemocrático o mercantilismo y las sociedades latinoamericanas, Ideas de Libertad”, 2010, No 75.

37 FRANK, R. H., Microeconomía \& Conducta, Madrid: MacGraw-Hill, 2006. 
lo dispuesto por el sistema hasta el momento en que el costo marginal de su cumplimiento se iguale a su beneficio marginal.

Por lo tanto, la regulación y el Sistema de Justicia Civil, como materia contemplada dentro del desarrollo de políticas públicas óptimas, no sólo tienen que ver con los mecanismos institucionales, sino también con las decisiones por parte de los agentes. Partiendo de esta afirmación, podremos analizar el problema del Sistema en mención tanto a nivel institucional como en el ámbito de la conducta individual y organizacional (ver gráfico 5). Es importante que tengamos presente que las políticas públicas expresadas a través de la regulación gubernamental (acto centralizado a cargo del Estado) implican coerción. Se requiere, por ende, una coerción mínima para que los ciudadanos de una comunidad o nación se defiendan, promuevan la evolución de la sociedad civil y disfruten de su trabajo. El uso de dicha coerción más allá del nivel mínimo requerido socava la libertad de los individuos, impidiéndoles por ejemplo efectuar una correcta asignación de los recursos.

Gráfico 5: Ranking de Calidad de la Burocracia Pública.

AL - Ranking del EIU de calidad de la burocracia pública del EIU

(Puntaje. $5=$ =levada, 1 =baja)

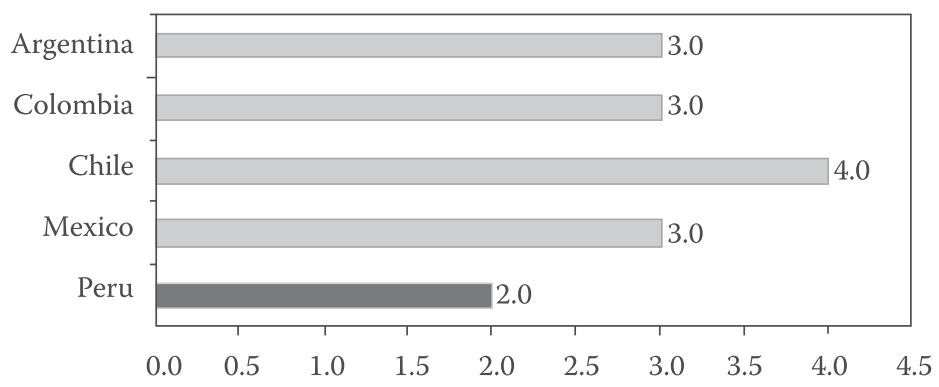

Fuente: Doing Business 2004, World Bank.

A pesar de esta necesidad, muchas herramientas de suma utilidad para estos fines, como el análisis costo-beneficio de las leyes, son continuamente dejadas de lado en Perú (ver gráfico 6). Esto constituye una situación que se ha mantenido constante sin dar señales de un cambio en el corto plazo. Esto constituye una situación preocupante en la medida que representa un escenario donde se acepta la afectación de uno de pilares de un sistema jurídico, como la prevalencia por el respeto por los derechos de propiedad. 
Gráfico 6: Últimos PL presentados y Análisis Costo-Beneficio.

Análisis de los 1125 últimos proyectos presentados según análisis costo beneficio (en porcentaje) El 94\% de los proyectos presentados o no presentan análisis costo beneficio o está mal hecho.

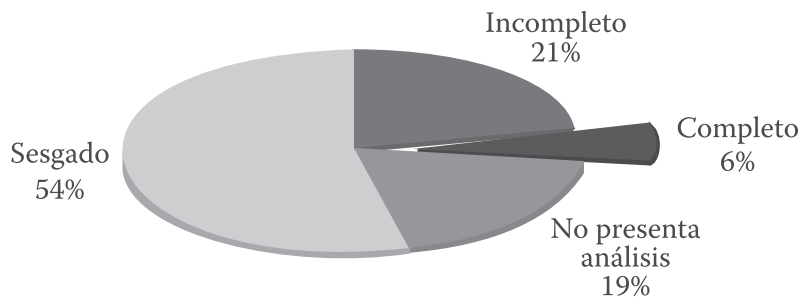

Fuente: Instituto Peruano de Economía.

En ese sentido, de acuerdo con The Heritage Foundation y The Wall Street Journal $^{38}$ en el Perú:

“(...) El Gobierno no brinda una eficaz protección a los derechos de propiedad privada. La EIU informa que el Poder Judicial peruano se encuentra plagado de corrupción. Desde principios del 2003, se está llevando a cabo un proceso de revisión interna, y el gobierno de Toledo comenzó su propio proceso de revisión en julio de 2003. La comisión interna presentó 158 recomendaciones, de las cuales 47 requieren aprobación legislativa. La comisión estima que necesitará \$390 millones de dólares estadounidenses para implementar los cambios, que están siendo revisados por el Gobierno."

Este rechazo por el uso de instrumentos técnicos no debería ser visto con escepticismo ni indiferencia por los distintos operadores del sistema legal. Pues, en realidad, permite un acercamiento de lo que sucede (lo que "es" o enfoque positivo) en el tejido social, lo cual debe de considerarse como un gran aporte.

Otra de las virtudes del uso de instrumentos radica en permitir ampliar nuestra visión crítica y dirigir estudios, evaluaciones, etc. de forma que resulte factible obtener interpretaciones y razonamientos judiciales más cercanos a la realidad, y, en consecuencia, que los agentes jurídicos no vivan inmersos en el mundo de los conceptos. Asimismo, a diferencia de lo que ocurre en el plano fáctico, se debe considerar que en el plano teórico la utilización de herramientas económicas para el análisis y el desarrollo institucional y organizacional del sistema se remonta a varios siglos atrás. Esta afirmación se verifica cuando nos

38 THE HERITAGE FOUNDATION y THE WALL STREET JOURNAL, Índice de Libertad Económica, The Heritage Foundation Press, 2012, p. 332. 
remitimos a los trabajos de autores como Cesare Beccaria (en el ámbito penal). ${ }^{39}$ Incluso, es conocido que, luego de una de una fase de letargo en el mundo anglosajón, el uso de la lógica económica para el entendimiento de la conducta humana fue retomado con fuerza por diversos economistas, entre los que destaca Gary Becker. ${ }^{40}$ Becker concibe la utilidad del enfoque económico en su capacidad para integrar una amplia gama de comportamientos en su análisis ${ }^{41}$, aplicándolo, a un gran número de temas como el estudio del sistema legal. Por lo tanto, el uso de instrumentos como el análisis costo -beneficio y en particular el Análisis Económico del Derecho (AED), de acuerdo a autores como Bullard:

"Este tipo de análisis nos permite aún sofisticar más la evolución de los efectos de una decisión legal. Hace algunos años, la entonces congresista Susy Díaz planteó un proyecto de Ley para sancionar a los violadores de menores con cadena perpetua. El proyecto recogió las simpatías de la población. Finalmente, la violación de menores es un delito tan grave que parecería haber consenso para que sea sancionado ejemplarmente. Como dijimos, la propensión a cometer un delito baja si el "precio" a pagar (sanción) sube. En esa línea la propuesta de Susy Díaz parece lógica para desincentivar ese tipo de delitos. Sin embargo el análisis debe ser integral, para contemplar todos los incentivos que afectan la conducta del potencial delincuente. El costo de delinquir se reduce con menor capacidad de detección. (...) Habrá quienes cuestionarán el análisis diciendo que no todos los delincuentes actúan así. De hecho, incrementen las penas y la posibilidad de detección a niveles óptimos.

39 Las primeras aplicaciones del razonamiento económico para el análisis de la conducta delictiva se remontan a autores como Cesare Beccaria (1738-1794), criminólogo, economista y jurista italiano, nacido en Milán. Él es considerado como uno de los más importantes expertos en asuntos penales de la historia. Sus tratados tuvieron una enorme influencia, llegando a convertirse en uno de los principales adversarios de la pena de muerte, la tortura y el trato cruel. Su obra fundamental, según los entendidos, es el "Tratatto dei Delitti e delle Pene", en donde propone la profunda reforma del sistema judicial en lo relacionado con lo criminal.

40 BECKER, G. S., "Crimen y Castigo" en Ensayos en Economia del Crimen y del Castigo con Landes, W. M., Chicago: University of Chicago Press, 1974. Gary Becker es uno de los economistas estadounidenses más importantes. Considerado como un "imperialista" de la ciencia económica, es decir, aquel que utiliza los instrumentos teóricos de la economía para explorar y "conquistar" nuevos territorios. En su tesis doctoral analizó las razones de la discriminación racial y sexual en la contratación laboral. En "Crimen y castigo"(texto básico el cual citaremos mas adelante) analiza la racionalidad del delincuente mediante el cálculo de probabilidades de los beneficios y costes del crimen. Obtiene el Premio Nobel de Economía en 1992 "por haber extendido el dominio del análisis "microeconómico" a un amplio campo del comportamiento y la interacción humanos, incluyendo comportamientos no mercantiles.

41 BECKER, G. S., The Economic Approach to Human Behavior, University of Chicago Press, 1976. 
Pero en todo caso ello no deslegitima el análisis efectuado, pues es evidente que, al menos en el caso de quienes actúan con esa racionalidad, el resultado será el señalado. La metodología seguida por el AED es incómoda para mantener la insania mental de los juristas esquizofrénicos. La metodología permite incorporar al análisis como se comportan seres de carne y hueso y cuáles son las consecuencias de la decisión que se tome. Ello puede conducir a perder consistencia conceptual, como si lo que importara es la consistencia entre dos conceptos y no la consistencia entre el concepto y la realidad"42.

Dentro de la perspectiva económica, el individuo de a pie (nuevamente visto como individuo racional), ${ }^{43}$ buscará maximizar su función de utilidad aunque esté sujeto a las restricciones impuestas por el mercado, realizando un análisis subjetivo de los beneficios y costos de sus acciones. Lo expuesto nos permite esbozar un modelo de conducta ${ }^{44}$ donde se puede representar de manera genérica la estructura de costos y beneficios de los principales agentes participantes del sistema procesal, los litigantes, efectuando un análisis introductorio del mismo.

\section{EN LA BÚSQUEDA DE UN MENOR COSTO SOCIAL}

La modernización del Sistema de Justicia Civil es un proceso que debe tener como objetivo la utilización óptima de los recursos destinados a sus funciones, internalizando dentro del modelo las restricciones impuestas por el marco institucional vigente. Esto es relevante pues en el Perú, la aplicación de perspectivas que hacen uso de la lógica económica para el análisis de las instituciones legales y sus operadores (AED), todavía suelen observase al Poder Judicial - del cual forma parte el Sistema Público de Justicia Civil- como independiente de todo tipo de presión del mercado político, evidenciando que el concepto de separación de poderes se considera un componente ceteri paribus.

Empero es necesario un cambio de orientación, pues en una realidad como la peruana, este tipo de asunciones pueden ser puestas en tela de juicio en la medida que existe una clara prevalencia de los Poderes Legislativo y Ejecutivo,

42 BULlARD G. A., "Esquizofrenia jurídica. El impacto del Análisis Económico del Derecho en el Perú", Themis, Revista de Derecho Segunda Época, Lima: Themis Editores, 2002, No 44.

43 Como señala FRANK, R. H., Microeconomía E Conducta, Op. cit., "ser racional significa tomar decisiones de acuerdo con el criterio del coste-beneficio, es decir, realizar una actividad si y sólo si los beneficios son superiores a los costes."

44 Los economistas y los abogados elaboran modelos conductuales. Los primeros usan los modelos de comportamiento para predecir respuestas a los cambios en los costos y beneficios percibidos al involucrarse en ciertos intercambios. Por su parte, los abogados consideran que el derecho permite moldear la conducta humana en términos de lo "socialmente aceptable". 
y en consecuencia, una afectación de la calidad del "enforcement" (aplicación) de la reglamentación. Como sostiene Ghersi ${ }^{45}$, esta es una variable relevante que se puede ilustrar a través de las áreas que todavía permanecen ajenas a la aplicación de los marcos legales y normativos del Estado. Lo expuesto ha sido representado a través de la medición del sector informal o economía subterránea (cuya evolución es descrita a través del gráfico 7) tradicionalmente descrita por Hernando de Soto et al. (1986) como la más esquiva a recurrir determinadamente al sistema de justicia. Siguiendo a este autor y observando las dimensiones de la economía informal en el Perú, seria entonces coherente asumir que la profundización de la aplicación de la justicia es todavía una tarea pendiente. A fin de ilustrar la dimensión de este sector presentamos el gráfico 7 que reproduce un informe conjunto del Ministerio de Trabajo y Promoción del Empleo (MTPE) y el Instituto Nacional de Estadística e Informática (INEI).

Gráfico 7: Sector Formal e informal 1987-2009 Perú.

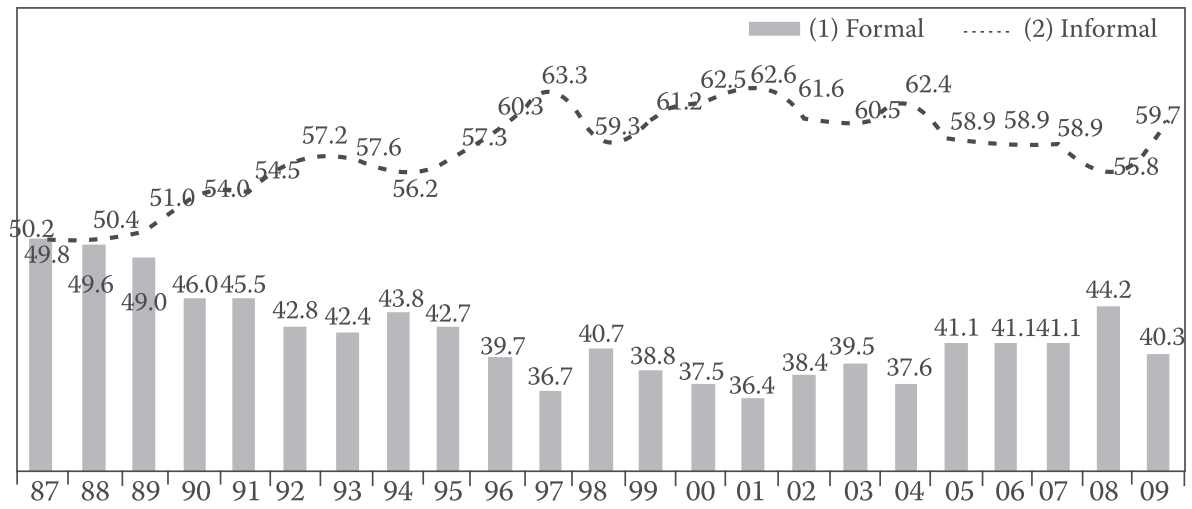

Fuente: MTPE, encuesta a niveles de empleo 1990-1996; convenio MTPE-INEI, Encuestas Nacionales de Hogares III trim 1997-2001; Para 2009 Informe estadístico Mensual del MTPE de enero 2010.

De igual forma, la Teoría de la Elección Pública, liderada por Buchanan y Tullock ${ }^{46}$, se muestra renuente a aceptar la consideración de la aplicación de un enfoque económico mas conservador, pues plantea serias dudas a la posibilidad de jueces independientes y a la supuesta motivación de que sea la eficiencia la que los impulse a ocupar puestos en la judicatura. Para lo cual,

45 GHERSI, S. E.,"El Costo de la Legalidad”, Centro de Estudios Públicos, Santiago de Chile: CEP Editores No 30, 1998, pp. 83-110.; y GHERSI, S. E., "La Economía Informal en América Latina". Cato Journal, vol. 7, No 1, 2005, pp. 1-14.

46 BUCHANAN, J. M. y Tullock, G., The Calculus of Consent: Logical Foundations of Constitucional Democracy, The University of Michigan Press, 1965. 
resulta imperativo delimitar claramente su campo de competencia permitiendo al sector privado participar de la provisión del servicio de justicia de modo más abierto (ampliando la penetración de mecanismos como la conciliación y el arbitraje). Además, a través de este proceso se debe:

a. Eliminar la duplicidad de funciones. No obstante la competencia sea de tipo facultativa y el demandante elija ante qué juez demandar y pedir "medidas cautelares", una vez efectuada la elección y resuelto el caso en contra del demandante, según lo dispuesto en la norma no debería por ende resultar factible que otro juez se pueda pronunciar sobre lo mismo, lo cual lamentablemente es pasado por alto.

b. Establecer mecanismos costo-eficientes: Estos mecanismos deben estar diseñados o contribuir a fortalecer la coordinación entre los agentes encargados del cumplimiento legal.

c. Eliminar de la esfera del denominado Sistema Público de Justicia Civil aquello que en una economía de mercado puede ser asignarse al sector privado. Esto significa establecer una regla clara que delimite la intervención Judicial en los casos que el sistema privado pueda proveer de un mecanismo eficiente para la solución de conflictos. Con respecto a este punto, podemos observar que no obstante la regla legal vigente establezca que la Instancia Judicial no puede pronunciarse sobre el fondo del laudo arbitral, esta funciona como un mecanismo dilator que incrementa, entre otros, los costes del proceso. Esta propuesta se vuelve relevante en la medida que los potenciales usuarios (litigantes) interioricen plenamente los costos y no solo los beneficios de sus acciones. Asimismo, para alcanzar una óptima asignación de los recursos, será necesario proveer al Sistema de Justicia de herramientas de gestión modernas.

Como marco para viabilizar nuestra propuesta normativa de modernización del Sistema de Justicia e inspirados por Peyrano ${ }^{47}$, efectuaremos una división en tres áreas complementarias pero no excluyentes.

- En la primera área, se debe intentar convertir el Sistema Judicial en lo que debe ser: un instrumento eficiente. Se debe, además, abordar el tema de la normatividad de la carrera judicial de manera que se estimule la excelencia y la competencia al interior del sector y se flexibilicen las disposiciones que puedan impedir contar con personal adecuado en todos sus niveles de decisión.

47 PEYRANO, J.W., "Eficiencia del sistema de justicia”, Revista Advocatus Nueva Epoca, No 7, Lima: Advocatus Editores, 2002, pp. 57-66. 
- En la segunda área, el objetivo debe consistir en racionalizar la estructura orgánica del Sistema de Justicia Civil con la finalidad de eliminar los altos costos administrativos. Se deberá trabajar para que no existan duplicidad de funciones y para que los procesos duren el menor tiempo posible sin colisionar con el nivel de calidad.

- En la tercera área, se deberá eliminar aquellos factores que afectan directamente a la ciudadanía. Por ejemplo, el tiempo en las colas o la facilidad para acceder a un servicio, de manera que se obtenga beneficios en el corto plazo, para lo que el ciudadano común debe ser un aliado en la búsqueda de un sistema más eficiente y transparente. Además, para obtener resultados positivos, es necesario relacionar a todos los actores del proceso en un mismo sentido. Alinear intereses, lo que permite evitar la aparición de una conducta oportunista ofree rider representada por aquellas manifestaciones de conducta según las cuales las personas actúan buscando beneficiarse de otros, sin ningún costo para ellos).

Igualmente, es común que el ciudadano de a pie relacione ineficiencia con el sector público. El servicio que se provee tiene una clara y criticable concepción monopólica pero el usuario no puede o debe recurrir a otras instancias u organizaciones a fin de efectivizar sus derechos. En general el personal del sector público no posee incentivos para dar el mejor trato posible a la ciudadanía (no obstante, subsisten organismos dentro del propio Estado que buscan romper este esquema). Consideramos saludable que, en la búsqueda de revertir esta situación, la organización Ciudadanos al Día, con el Apoyo de la Defensoría del Pueblo y la Internacional Finance Corporation (IFC) está organizando la primera edición del Premio a la Buenas Prácticas Gubernamentales, competencia de carácter anual que busca reconocer las prácticas en el Sector Público orientadas a brindar mejor servicio a la ciudadanía.

Visto desde otra perspectiva, la reorganización no generará resultados consistentes con el Criterio de Pareto si estos no son acompañados de cambios en los mecanismos con que se opera. Y, lo más importante, no es probable que la reorganización se produzca si no se tiene la certeza de que se va a obtener un cambio. Ello porque la reorganización implica un costo que pocos van a estar dispuestos a asumir si no están seguros de que con el cambio se va a obtener el beneficio concreto de un mejor servicio, lo que se condice de manera general con el principio de racionalidad.

No se trata de un juego de Suma Cero, sino que, por el contrario, se debe encontrar arreglos de reestructuración en que se gane tanto en términos de costos como de capacidad para cumplir con los objetivos organizacionales 
(Suma Positiva). La utilización eficiente de los recursos, al ser uno de los principales objetivos de la modernización del Sistema de Justicia, implica mejoras en el costo, la calidad y alcance de los servicios que presta.

La primera de las variables es la que se menciona más cuando se aborda el tema de la reforma o modernización del aparato burocrático (del cual forma parte el Sistema de Justicia) y es, en alguna medida, la más preocupante de las tres, lo que no significa necesariamente que sea el único que deba abordarse en este momento. Lo cual se explica con menor o mayor grado de facilidad dados los actuales problemas de caja fiscal y el amplio porcentaje que representa el gasto corriente dentro del presupuesto

Somos conscientes que resulta sumamente complicado incorporar las variables calidad y alcance y/o penetración del sistema (provisión del servicio) cuando al frente tenemos problemas como baja recaudación fiscal y se persiste en una provisión mayormente pública (directamente dependiente del volumen de las arcas del estado y del nivel de compromiso de los políticos y funcionarios de turno). En el Perú, tradicionalmente, esta situación se ha intentado corregir con un incremento en la cantidad de tributos (sin profundizar lo suficiente en cuestiones también relevantes como el nivel de estrés y presión impositiva). En este sentido, los tributos son mayormente presentados como el mecanismo idóneo pues permiten recabar información sobre la actividad de los contribuyentes y asimismo incorporarles a la economía formal y al sistema legal. Sin embargo, los resultados obtenidos en términos de incorporación de un mayor numero de contribuyentes y en consecuencia, el éxito del enfoque de formalización son todavía discutibles (ver la evolución del empleo informal ilustrada por el gráfico 8)

Gráfico 8: Evolución del empleo informal y variación del PBI per-cápita, 2001-2009 (en \%).

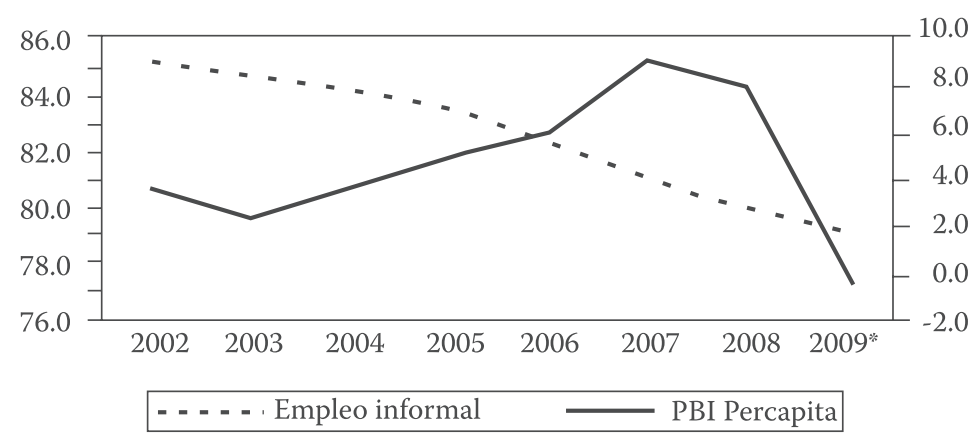

Fuente: MTPE (2010). “Trabajo informal y protección social”. WIEGO-CIES 
Por otra parte, las labores por mejorar el nivel de calidad y de alcance en la provisión de justicia civil tienden a parecer todavía poco fructíferas. No obstante, los esfuerzos efectuados por llevar a cabo un Proceso de Reforma del Sistema de Justicia en general no solucionan los problemas de fondo ${ }^{48}$. Lo que se refleja, claramente, en una cada vez mayor carga procesal, que supera de lejos la capacidad instalada del Sistema. No obstante, somos conscientes de que la sobrecarga procesal no es el principal problema del sistema público de justicia civil. De existir un mayor número de magistrados, no se podría asegurar que existirá una relación de directa proporcionalidad con el nivel de calidad y celeridad de la justicia, pues el factor de mayor relevancia es el tipo de magistrado (capacitación del personal) partícipe del sistema. Una mejora sustantiva se podría lograr si se mejora y reduce el intervalo de tiempo en el que se efectúa el control de conducta de los jueces (7 años en promedio), si sólo no se sanciona a un juez corrupto en caso de delito flagrante o por cuestiones de orden disciplinario y funcional. Esto significa la necesidad de introducir estándares para sancionar el error o la mala intención (dolo) y negligencia en relación al resultado esperado. Los controles (no obstante severos), no deben seguir un trámite burocrático poco iluminado.

Consideramos que la urgencia ha hecho que no se enfoque el problema de manera integral y que no se permita el desarrollo de incentivos para que la situación se revierta y para que la calidad y cobertura mejoren, lo que permitiría además garantizar un sistema menos costoso. Normalmente, cuando se fuerza una reducción de costos, ${ }^{49}$ por parte de una entidad pública, la teoría económica nos indica que el Estado traslada este costo a la sociedad ${ }^{50}$. El hecho de que el Sistema de Justicia sea de facto monopólico y que no exista la cultura de servir de la mejor manera posible al ciudadano de a pie hace que este traslado sea muy natural y, por ello, se debe permitir eliminar las barreras para la aparición de incentivos concretos que reviertan la actual situación ${ }^{51}$.

Por lo tanto, para que el esquema propuesto funcione, es necesario que en la tarea de modernización se invierta tiempo en el desarrollo de indicadores que permitan evaluar el nivel y calidad de servicio y gestión, los cuales deberán tener

48 PEYRANO, J.W. Op. cit., pp. 57-66.

49 Que debe efectuarse con un criterio técnico y dejando al margen la prevalencia de consideraciones oportunistas de parte de los que ostentan el poder político.

50 TULLOCK, G., "Barreras de entrada en política”, Democracia y Economía Política (compilación de Antoni Casahuga Vinardell), Barcelona: Universidad Autónoma de Barcelona, 1980, pp. 131-144.

51 HELLMAN, J. and KAUFMANN, D., "La captura del Estado en las economías en transición”. Finanzas y Desarrollo, No 38, Vol. 3, 2001, pp. 31-35. 
en consideración no sólo el costo con que se brinda el servicio de justicia, sino los costos que se imponen a la sociedad. Adicionalmente, el sistema de indicadores debe de servir como una herramienta de control de eficiencia para evitar las arbitrariedades y la prevalencia de la corrupción y mediocridad de los agentes en el sistema.

\section{CONClusiónes}

En conclusión, si recordamos lo expuesto al inicio del presente escrito, se puede deducir que como consecuencia de la aparición de factores externos:

1. Los individuos que inicien un proceso legal probablemente no logren obtener un resultado eficiente a pesar del esfuerzo desplegado. Como consecuencia de esto, no se producirá una situación que pueda conjugarse con alguno de los tres estadios de eficiencia anteriormente descritos, que dicho de otro modo es el equivalente a sostener que la Sociedad Pierde.

2. De lo anterior, se desprende que como consecuencia de la aparición de externalidades los costos de los procesos pueden tornarse insostenibles para los querellantes.

3. Si la aparición de externalidades supera el ámbito de riesgo en el que cada individuo incurre al iniciar un proceso (por ejemplo contratar un mal abogado) y toma forma de un factor externo negativo (ejemplo: jueces corruptos), se tendrá como consecuencia un desincentivo en los individuos para recurrir al Sistema de Justicia a fin de solucionar sus conflictos. Lo que puede, a la larga, acarrear la aparición de otras externalidades como la búsqueda de justicia por propia mano ante la desconfianza generalizada en el sistema. Estos desincentivos tienden a direccionar a la sociedad hacia una situación adversa como es la de caos social en la que impera una total desconfianza hacia entidades que buscan la prevalencia de un orden social ${ }^{52}$ y la coexistencia pacífica entre individuos (Poder Judicial).

4. Al referirnos a la justicia civil, debemos indagar con mayor profundidad sobre su carácter privado. Esto es así, pues son los litigantes quienes hacen suyo el beneficio que reporta el (proceso) y sólo en algunos aspectos, presenta carácter público.

5. Desde una perspectiva económica, podemos considerar más eficiente que ciertos bienes que como la justicia civil exhiben un carácter privado, sean provistos de forma competitiva y que los costos generados sean asumidos por los participantes del Sistema, pues de esa manera la demanda por el bien se colocará en niveles óptimos. Solo en aquellos supuestos donde, aparen-

52 BARRY, N. "The tradition of Spontaneous Order", Op. cit. 
temente, el bien justicia presente un carácter predominantemente público (por ejemplo, la casación y la justicia constitucional) el Estado, debe asumir el reto de su producción y financiamiento.

6. En el Perú, la profundización de la aplicación de la justicia civil es todavía una tarea pendiente. En este sentido, el modo de entender la aplicación (enforcement) de las leyes y por consiguiente el carácter (naturaleza) del sistema de justicia civil requiere de un giro radical. En este sentido, instrumentos como el análisis económico del sistema legal resultan relevantes. Sin embargo, este tipo de enfoques deben evitar caer en aproximaciones y asunciones conservadoras. Esto es así, en la medida que el Perú todavía muestra señales que la equivalencia entre Poderes del Estado es un horizonte todavía lejano. Este tipo de premisas se ven ilustradas por un número importante de variables. En ese sentido, consideramos que futuros ejercicios empírico complementarios (ej. correlación de variables), no solo constituyen una carencia dentro del ámbito académico peruano, sino también una necesidad con miras a proveer una mejor ilustración y diseño del sistema de justicia civil.

\section{REFERENCIAS}

ALONSO, J.A. and GARCIMARTIN, C., Collective Action and Development. The Role of Institutions, Madrid: Editorial Complutense, 2008.

ARGOÑA, A., "Values, Institutions and ethics", Working Paper No 215, IESE Business School - University of Navarra Press, 1991.

ACEMOGLU, D. and JOHNSON, S., "Unbundling Institutions", Journal of Political Economy, vol. 113, No. 5, 2005, pp. 949-995.

AOKI, M., Toward a Comparative Institutional Analysis, Cambridge - Mass: MIT Press, 2001.

AXALA, G. \& FABRO, J., “ ¿El Impacto de la calidad institucional sobre el crecimiento económico depende del nivel inicial de renta?". Economic Affairs, No 28, vol. 3, 2008, pp. 45-49.

BARRY, N., "The tradition of Spontaneous Order", Laissez-Faire, No 6, pp. 1-43, UFM Press, 1997.

BASSANINI, A., SCARPETTA, S. and HEMMINGS, P., Economic growth: the role of policies and institutions. OECD Press, 2001.

BAUMOL, W. J., "Entrepreneurship: Productive, Unproductive, and Destructive", The Journal of Political Economy, Vol. 98, No. 5, 1990, pp. 893-921.

BAYLY LETTS, A. y PASQUEL RODRÍGUEZ, E., “¿Quién dijo que en Salem hubo brujas? La privatización del servicio de justicia: rompiendo el mito de la 
justicia estatal", Lima: Themis Revista de Derecho Segunda Época, No 46, 2003, pp. 315-346.

BECKER, G. S., "Crimen y Castigo" en Ensayos en Economia del Crimen y del Castigo con Landes, W. M., Chicago: University of Chicago Press, 1974. Press, 1976. , The Economic Approach to Human Behavior, University of Chicago

BECKER, G. S., "Una teoría de la Competencia entre grupos de presión por influencia política. Cuadernos Trimestrales de Economía”, No 98, 1983, pp. 371-373.

BENEGAS-LYNCH, A., "Bienes públicos, externalida- des y los free-riders: el argumento reconsiderado", Estudios Públicos, Santiago de Chile: CEP Editores, No 71, 1998, pp. 203-218.

"El Conocimiento y la Ciencia: Algunas Consideraciones Hayekianas". Revista de Economía y Derecho, Lima: UPC, No 2, vol. 5, 2005, pp. 13-26.

BLIND PK., Building Trust in Government in the Twenty-first Century: Review of Literature and Emerging Issues, Austria: UNDESA, 2006.

BLUNDELL, J. and ROBINSON, C., "La Regulación sin el Estado", : Revista Libertas, Buenos Aires: ESEADE, No 32, 2000, pp. 4-22.

BUCHANAN, J. M. y Tullock, G., The Calculus of Consent: Logical Foundations of Constitucional Democracy, The University of Michigan Press, 1965.

BUllard G. A., Estudios de Análisis Económico del Derecho, Lima: Ara Editores, 1996, p. 228.

, "Esquizofrenia jurídica. El impacto del Análisis Económico del Derecho en el Perú", Themis, Revista de Derecho Segunda Época, Lima: Themis Editores, 2002, No 44.

CÁCERES, R., Institutions, Law and Cost of Transaction. Lima: Pacific University Press, 2005.

CALABRESI, G. and MELAMED, A. D., "Property Rules, Liability Rules and Inalienability: One View of the Cathedral", Harvard Law Review, Vol. 85, 1972, p. 108.

COASE, R. H., “The Nature of the Firm”, Económica, No 4, Vol. 16, 1937, pp. 386-405. 1960, pp. 1-44.

, "The Problem of Social Cost", Journal of Law and Economics, 1(3), , La Empresa, el Mercado y la Ley, Madrid: Alianza Economía, 1994. 
COBIN, J. M., Políticas Públicas: Tópicos Modernos de la Economía de Mercado para el Bienestar Social, Santiago de Chile: Fondo Editorial Universidad Andrés Bello, 2009.

CONSEJO NACIONAL DE LA MAGISTRATURA, Informe de la Secretaría Técnica de Selección y Nombramiento, Lima: CNM Editores, 2012.

CÓRDOVA, D., "La nueva economía institucional y el análisis del subdesarrollo en América Latina", Revista de Economía y Derecho, No 2. Lima: Universidad Peruana de Ciencias Aplicadas, 2004, pp. 7-23.

DIEZ CANSECO NÚÑEZ, L. Y PASQUEL RODRÍGUEZ, E., "Stare decisis, intercambios comerciales y predictibilidad: una propuesta para enfrentar la reforma del Poder Judicial". Revista de Economía y Derecho, No 2. Lima: Universidad Peruana de Ciencias Aplicadas, 2004.

EPSTEIN. R. A., Principios para una sociedad libre (traducción del libro Principles for a Free Society. Reconciling Individual Liberty with the Common Good), Lima: Universidad Peruana de Ciencias Aplicadas Editores, 2003.

, "Imposición, regulación y confiscación", Revista de Economía y Derecho, No 1, Lima: Universidad Peruana de Ciencias Aplicadas, 2004 pp. 45-60.

FOSS, N. J. and KLEIN, P. G., "Alertness, Action, and the Antecedents of Entrepreneurship”, The Journal of Private Enterprise, Vol. 2, 2010, pp. 145-164.

FRANK, R. H., Microeconomía \& Conducta, Madrid: MacGraw-Hill, 2006.

FURUBOTB, E. G. and RICHTER, R., Institutions and Economic Theory. The Contribution of the New Institutional Economics. Michigan: The University of Michigan Press, 1998.

GHERSI, S. E., "Economía de la Corrupción”, Centro de Estudios Públicos, Santiago de Chile: CEP Editores No 73, 1991, pp. 3-20.

, "El Costo de la Legalidad", Centro de Estudios Públicos, Santiago de Chile: CEP Editores No 30, 1998, pp. 83-110.

, "La Economía Informal en América Latina". Cato Journal, vol. 7, No 1, 2005, pp. 1-14.

, "The competitive character of the Sources of Law", Revista de Instituciones, Ideas y Mercados, No 47, 2007, pp. 89-109.

El capitalismo antidemocrático o mercantilismo y las sociedades latinoamericanas, Ideas de Libertad, 2010, No 75.

GERBER, E. R., The Populist Paradox: Interest Group Influence and the Promise of Direct Legislation. Princeton: Princeton University Press, 1999. 
HART, H. L. A., El Concepto de Derecho. México: Editorial Nacional, 1980.

HAYEK, F. A., Law, Legislation and Liberty, University of Chicago Press, 1978.

HELLMAN, J. and KAUFMANN, D., "La captura del Estado en las economías en transición”. Finanzas y Desarrollo, No 38, Vol. 3, 2001, pp. 31-35.

HIRSHMAN, A.O., Interés Privado y Acción Pública. F.C.E. México, 1986.

INSTITITUO APOYO, Reforma del Poder Judicial, Lima: Instituto Apoyo Ed., 2010, p. 22;

KELSEN, H., ntroducción a la Teoría Pura del Derecho. Lima: Asociación Peruana de Derecho Constitucional, 2001.

KIRZNER, I. M., "Equilibrium versus Market Process", The Foundations of Modern Austrian Economics, Kansas City: Sheed and Ward Inc., 1976.

LANDSBURG, S. E., El economista en pijama (traducción de Alejandro Tiscornia), Buenos Aires: Editorial Atlántida, 1995.

MÉNDEZ, R. C. B., "Institutional Innovation, Deregulation and Competition in a Structured Society”. HDR Expo 2011, Sydney: Macquarie University Faculty of Business and Economics Press, 2011.

, "Entrepreneurship, Institutions in a Changing Environment", URJC and IJM - VI Austrian Economics Conference. Madrid: URJC/Instituto Juan de Mariana, 2013.

, "An Introduction to Institutional Coordination", Working paper GLEA Lecture Series 2013, Italia: Free University of Bolzano, 2013.

, "Strucured, Transitional amd Unstructures Societies: An Alternate Taxonomy to improve testing positive institutional interaction and the economic of rules", Working Paper - ISLE Conference 2013, Switzerland: Universitá della Svizzera Italiana, 2013.

MOSTERIN, J., "Herencia genética y transmisión cultural", Evolución, vol. 7, no 12, 2012, pp. 71-86.

MENGER, C., Principles of Economics. Institute for Humane Studies, 1871, ed. de 1976.

MISSES, L. von, La acción humana, Madrid: Unión Editorial, 1980.

NORTH, D., Growth and Structural Change, New York: W. W. Norton, 1981.

, Institutions, Institutional Change and Economic Performance, Cambridge: Cambridge University Press, 1990. 
pp. 97-112.

"Institutions", Journal of Economic Perspectives, Vol. 5, No. 1, 1991, "Economic Performance Through Time", American Economic Review, Vol. 84, No. 3, 1994, pp. 359-368.

, Understanding the Process of Economic Change, New York: Princeton University Press, 2005.

OSTROM, E., Governing the Commons: The Evolution of Institutions for Collective Action, Cambridge: Cambridge University Press, 1990.

PEÑA C. G., Correa S., J. y Vargas, J. E., "El rol del Estado y el mercado en la justicia", Cuadernos de Análisis Jurídico, Santiago de Chile: Universidad Diego Portales y Fundación Ford, 2001.

PEYRANO, J. W., "Eficiencia del sistema de justicia", Revista Advocatus Nueva Epoca, No 7, Lima: Advocatus Editores, 2002, 2002, pp. 57-66.

PICKER, P., "Una introducción a la teoría de juegos y el Derecho", El Análisis Económico del Derecho y la Escuela de Chicago. Lecturas en honor a Ronald Coase. Eric A. Posner (compilador). Lima, Universidad Peruana de Ciencias Aplicadas, 2002, pp. 72 y 78.

PODER JUDICIAL DEL PERÚ, "Reporte Magistrados del Poder Judicial a nivel nacional”, Revista Poder Judicial, Lima: PJ Editores, 2010, p. 3;

SARDÓN, J. L., La Constitución Incompleta, Lima: Instituto Apoyo, 1999.

SIEGAN, B. H., Reforma Constitucional, Lima: Centro de Investigación y Estudios Legales, 1993.

SOLIMANO R., A., TANZI, V. y DEL SOLAR, F. S., Las termitas del Estado: ensayos sobre corrupción, transparencias, Santiago de Chile : Fondo de Cultura Económica, 2008.

SUNSTEIN, C. R., "Análisis Conductual del Derecho", Revista Advocatus Nueva Época, Lima: Advocatus Editores, No 9, 2003, pp. 57- 74.

"Heurística moral", Revista Advocatus Nueva Época, Lima: Advocatus Editores No 10, 2004, pp. 27-39.

STIGLER, G., The Economist as Preacher, and Other Essays, Chicago: University of Chicago Press., 1982 pp. $455-68$.

, "Law or Economics?" Journal of Law and Economics, No 35, 1992,

TIROLE, J., "The Internal Organization of Government", Oxford Economic Papers, Vol. 46, No. 1, 1994, pp. 1-29. 
THE HERITAGE FOUNDATION y THE WALL STREET JOURNAL, Índice de Libertad Económica, The Heritage Foundation Press, 2012, p. 332.

TULLOCK, G., "Barreras de entrada en política”, Democracia y Economía Política (compilación de Antoni Casahuga Vinardell), Barcelona: Universidad Autónoma de Barcelona, 1980, pp. 131-144.

VOIGT, S., "How to Measure the Rule of Law", 2009, Available at SSRN: http://ssrn.com/abstract=1420287 or http://dx.doi.org/10.2139/ssrn.1420287

WEBER, M., Economía y Sociedad, Vol. I, p. 632, México: Fondo de Cultura Económica, 1964.

WILLIAMSON, C., "Informal institutions rule: institutional arrangements and economic performance", Public Choice 139, 2009, pp. 371-387

\section{LEGISLACIÓN}

Constitución Peruana de 1993, Arts. 61 y 65.

Código Civil Peruano - Decreto Legislativo VII del título preliminar

Código procesal Civil art. 400 - Resolución Ministerial № 010-93-JUS.

\section{LISTADO DE INTERNET}

Poder Judicial, visitada el 2 de setiembre, 2012, www.pj.gob.pe.

Congreso de la República, visitada el 7 de setiembre, 2012, www.congreso.gob.pe.

Fundación Libertad y Progreso, Índice de calidad Institucional 2012, visitada el 19 de enero, 2013, http://www.libertadyprogresonline.org/category/calidadinstitucional/indicedecalidadinstitucional/

Índice de Libertad Económica 2013, visitado el 2 de mayo, 2013, http://www. heritage.org/index/

Instituto Peruano de Economía (IPE), visitada el 12 de setiembre, 2012, www. ipe.org.pe

Latinobarometro, visitada el 14 de agosto, 2013, www.latinobarometro.org

Ministerio de Economía y Finanzas, visitada el 2 de setiembre, 2012, www. mef.gob.pe.

Ministerio de Trabajo y Promoción del Empleo, visitada el 5 de setiembre, 2012, www.mtpe.gob.pe.

World Value Survey, visitada el 12 de agosto, 2013, www.worldvaluessurvey.org

World Bank Group - Doing Business 2004, visitada el 10 de agosto, 2012, www. doingbusiness.org

World Economic Forum 2002, visitada el 10 de agosto, 2012, www.weforum. org/world-economic-forum-usa 